\title{
ANALYSIS AND ASSESSMENT OF ENERGY EFFICIENCY OF PASSENGER LIFTS
}

\author{
Tomasz Krakowski' ${ }^{1}$, Hubert Ruta ${ }^{1}$
}

1 AGH University of Science and Technology, Faculty of Mechanical Engineering and Robotics, Department of Rope Transport, A. Mickiewicza Av. 30 (B2-p12), 30-059 Kraków, Poland, e-mail: krakowsk@agh.edu.pl

Received: 2018.06.27

Accepted: 2018.08.07

Published: 2018.09.01

\begin{abstract}
The energy performance and operational characteristics of the passenger lift investigated in this study were based on energy consumption data registered throughout the normal duty cycle. An overview is provided of available methods employed to evaluate the energy uptake of passenger lifts, relying mostly on energy consumption measurements taken on a real object over an idealised reference duty cycle. Measurement data were used to determine the energy efficiency rating of the lift during the trip cycle and in the standby mode and the energy demand levels, which are then to be compared with measurement results obtained under the service conditions.
\end{abstract}

Keywords: passenger lifts, energy efficiency, diagnostics.

\section{INTRODUCTION}

New developments in lifts and hoisting installations enhance their safety features and ride quality, at the same time improving their energy efficiency, which is of great importance particularly in the context of growing pressure exerted by state institutions and international organisations to promote environmental considerations. In the last few decades several important regulations were introduced, aimed to reduce the atmospheric emissions of greenhouse gases [1, 6, 20]. Most recent decisions were made at the United Nations conference held in Paris in 2015, recommending the actions to be taken to prevent the worldwide temperature increase by $2^{\circ} \mathrm{C}$ by 2100 in relation to the temperature levels prior to the industrial revolution. Thos participating in the conference agreed to make every effort so that the temperature should not increase by more than $5^{\circ} \mathrm{C}$ [1].

As regards the reports on operation of lifts and hoisting installations in the literature world-wide, the area is now well studied. Besides, the available studies focus mainly on the user's comfort associated with acoustic emission [14], dynamic over- loading acting upon passengers during the ride $[8$, $9,10,16]$ and investigations of the selected lift subassemblies performance [11, 12, 13, 20].

The first research efforts to evaluate energy efficiency were made in the 1980 s, the issue was addressed in the works by J.Schroeder [22, 23, 24, 25] and L.E. White [29], later it was raised by other authors [2, 3, 5, 7, 15, 17]. In 2005 Harvey M.Sachs in his work Opportunities for Elevator Energy Efficiency Improvements conducted a thorough analysis of the lift installation industry in the USA [21]. An important publication having relevance to Europe was the report that appeared upon completion of the major research project Energy Efficient Elevators and Escalators in 2010 [4]. A team from the Coimbra University together with researchers from Europe (ELA), Italy (ENEA), Germany (ISI) and Poland (KAPE) investigated the energy efficiency of 74 lift installations in Portugal, Italy, Germany and Poland. The results have shown that energy consumption by lifts accounts for 3-5\% of the overall building electricity use whilst the total energy uptake by lifting installations in the EU countries approaches 18 TWh [4]. 
Methodology of measurements used in the E4 project was based on the regulations set forth in the document SIA 380/4 ElektrischeEnergieimHochbau [26]. In 2009 the Association of German Engineers set guidelines VDI 4707 part I [27] and part II appeared 2013 [28]. The document provides the energy efficiency classification of passenger lifts. In 2013 the standard PN EN ISO 25745-1:2013 [18] was developed, with the main focus on measurement procedures. Its first version provided a calculation algorithm, whilst part II developed in 2015 is focused on available methods to estimate electricity consumption. The standard PN EN ISO 25745-1:2015 [19] lays down the procedures for energy efficiency labelling of passenger lifts.

\section{METHODOLOGY OF ESTIMATING THE ELECTRICITY CONSUMPTION BY PASSENGER LIFTS}

All methods employed in assessments of energy taken by passenger lifts $[4,19,27]$ rely on measurements of electricity consumption by the investigated lift. Measurement are taken for an idealised duty cycle of the lift installation and the actual measurement procedure is specified in the standard [18]. Prior to the calculations, energy consumption has to be registered in the travel mode (a reference trip cycle mode and a short trip reference cycle mode) and in the non-running mode, when the lift remains idle (on standby).

The methodology employed while conducting the Project E4 relied on energy uptake data registered throughout the reference trip cycle and power demand on the standby derived from the value registered 5 minutes after completion of the ride. The reference trip cycle is defined as the lift duty cycle whereby the cab travels between the terminal landings in both directions, including the time required to open and close the door. In the light of the standard [19], the energy uptake has to be registered during a short cycle reference trip, which involves the travel distance equal to $25 \%$ of the maximal distance over which the lift travels at the nominal speed. Standby mode testing involves the measurements of power uptake 5 minutes after the lift stops, 5-30 minutes and 30 or more minutes after the stop. This approach has been adopted to take into account the presence of energy saving systems in the standby mode which shut-off the selected ancillary systems.
Lift energy estimation methodologies underlying the project E4 and the guidelines VDI 4707 are fairly straightforward, though without consideration of several influencing factors associated with operational characteristics of a real lift, such as incorporation of energy saving systems in the standby mode. Besides, respective factors collated in [4] taking into account the rated load and the distance travelled fail to account for the differences between the lift usage patterns and locations, treating all lift installations as one category. The standard VDI 4707 provides five usage categories, according to the usage pattern of an investigated lift, the average travel and idle times and the actual locations of the investigated object. This categorisation determines the values of coefficients having relevance to travel time and idle time which impact on the accuracy of further calculations. Thus usage category allows for discriminating the usage profiles of investigated installations. The guideline VDI 4707 part I is the first document providing the energy efficiency category of a lift installation. The energy efficiency category (A-G, A being the best-in class) is assigned taking into account the usage category and the overall energy demand of the lift installation.

The standard PN-EN ISO 25745-2:2015 [19] provides the most advanced and sophisticated method of estimating the energy uptake by a passenger lift, being an updated version of the method employed in the earlier version. A major advantage of this approach is that it accounts for a wide spectrum of factors determining the actual energy consumption by a lift. Attempts are made to include and accordingly model all influencing factors which were not given due consideration in the earlier documents. Each lift is assigned to one of the six usage categories, and this categorisation to a large extent determines the result of further calculations and underlies the choice of coefficient values to express the lift usage patterns. Parameters recalled in the procedure include the average travel distance, rated load, idle time and standby time.

\section{METHODOLOGY AND RESULTS OF MEASUREMENTS}

Measurements were taken on a lift operated in one of the AGH-UST buildings in 2016. It is a machine room-less (MRL), gearless permanent magnet synchronous traction machine (Fig 1) with microprocessor control and speed regulation via a frequency converter. Key parameters of the lift installation are collated in Table 1. 


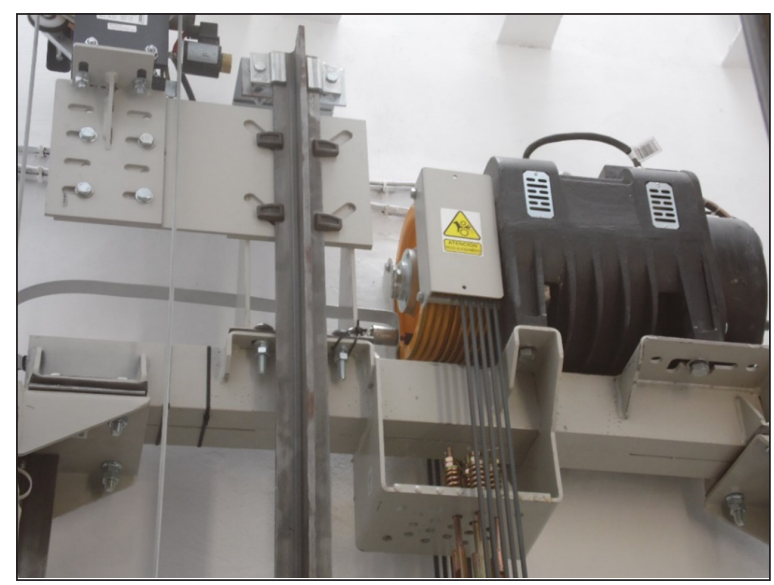

Fig. 1. Hoist drive

The measurement equipment comprises a KEW 6310 power quality analyser (Kyoritsu), voltage sensors and the KEW8125 (AC500A) clamp-on meter for inrush current measurements in the range 0-500 A. The measurements system is connected to the drive circuit in the lift installation (Fig. 2), parameters registered whilst in service included: phase voltage, phase current intensity, active and apparent power, power factor and the phase angle.

Measurements were taken in accordance with the procedures set in [18], i.e. during the reference trip cycle, a short cycle reference trip and on the standby, for 60 minutes after the lift stopped. Respective parameters were also registered under the normal operating conditions of the lift installations, over a weekly duty cycle. This approach affords us the means to determine the energy efficiency category of the installa-

Table 1. Technical specification of the investigated lift

\begin{tabular}{|c|c|}
\hline Date of manufacture & 2016 \\
\hline Rated load & $630 \mathrm{~kg}$ \\
\hline Rated speed & $1 \mathrm{~m} / \mathrm{s}$ \\
\hline Roping & $2: 1$ \\
\hline Number of stops & 5 \\
\hline Hoisting height & $14,8 m$ \\
\hline Hoist drive type & $\begin{array}{l}\text { MPGO! EVOLUTION } \\
\text { (MRLG630AA) }\end{array}$ \\
\hline Motor power rating & $5 \mathrm{~kW}$ \\
\hline Sheave diameter & $\varnothing 240 \mathrm{~mm}$ \\
\hline Control unit & $\begin{array}{l}\text { MicroBasic micropro- } \\
\text { cessor control with } \\
\text { frequency converter }\end{array}$ \\
\hline Landing door & automatic \\
\hline Car door & automatic \\
\hline
\end{tabular}

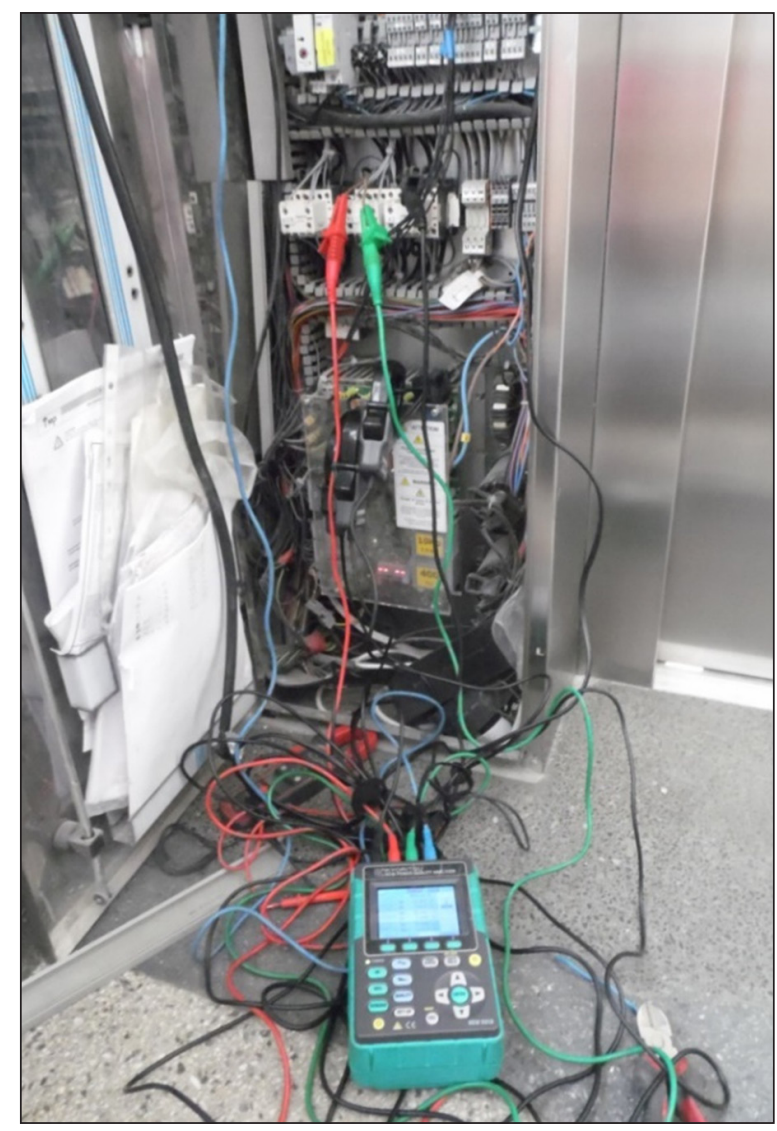

Fig. 2. KEW6310 power quality analyser connected to the drive circuit

tion, and its energy performance and operational characteristics, and to draw a valid comparison of predicted energy uptake data based on $[4,19$, 27] with the real energy consumption within the analysed period of time.

Time dependencies of active power and energy uptake by the main circuit in the lift registered during the reference trip are shown in Fig 3 , those obtained for the short-cycle reference trip are given in Fig 4. These are most typical profiles revealing a higher instantaneous power levels and higher energy uptakes during the downward trip because of the empty car trip and the need to hoist the counterbalance, its weight being roughly equal to the weight of the car plus $50 \%$ of its rated load.

Fig. 5 plots the energy consumption by the lift in the standby mode. The registration began immediately after the end of the trip. The plot reveals a change of the inclination angle with respect to the horizontal axis in the 15th minute, which is indicative of the reduced energy demand due to the lift remaining idle. There is a system limiting the energy consumption through 


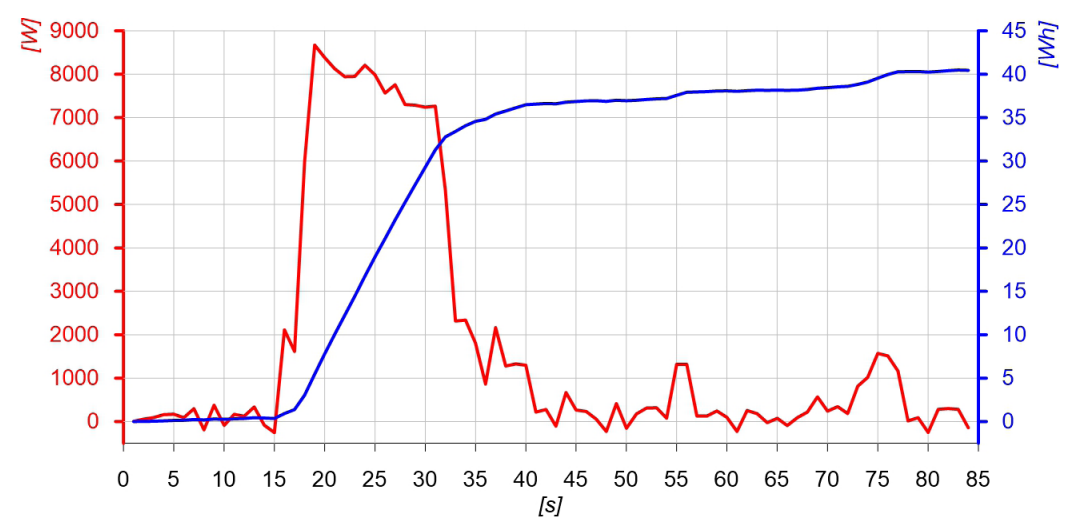

Fig. 3. Active power $[\mathrm{W}]$ and energy consumption $[\mathrm{Wh}]$ during the reference trip cycle

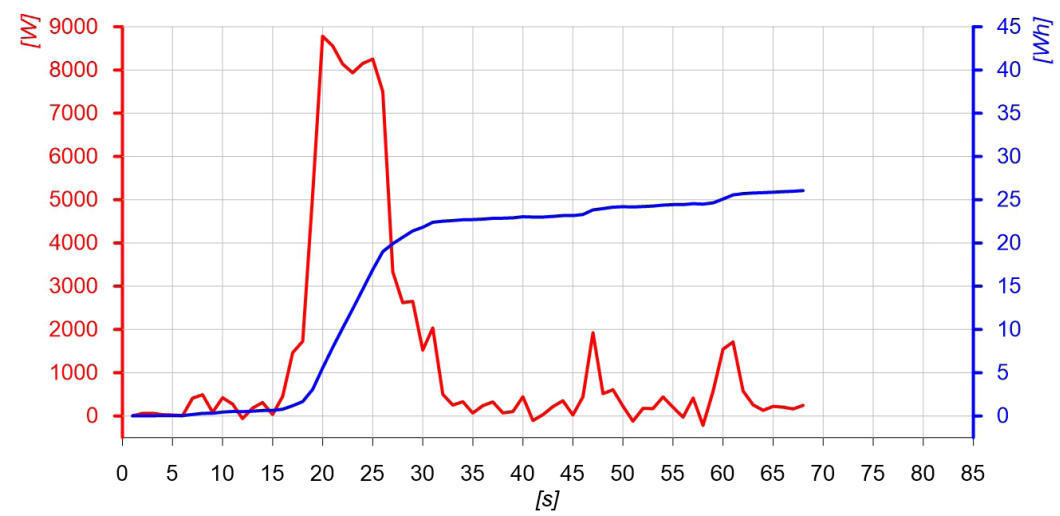

Fig. 4. Active power [W] and energy consumption [Wh] during the short-cycle reference trip

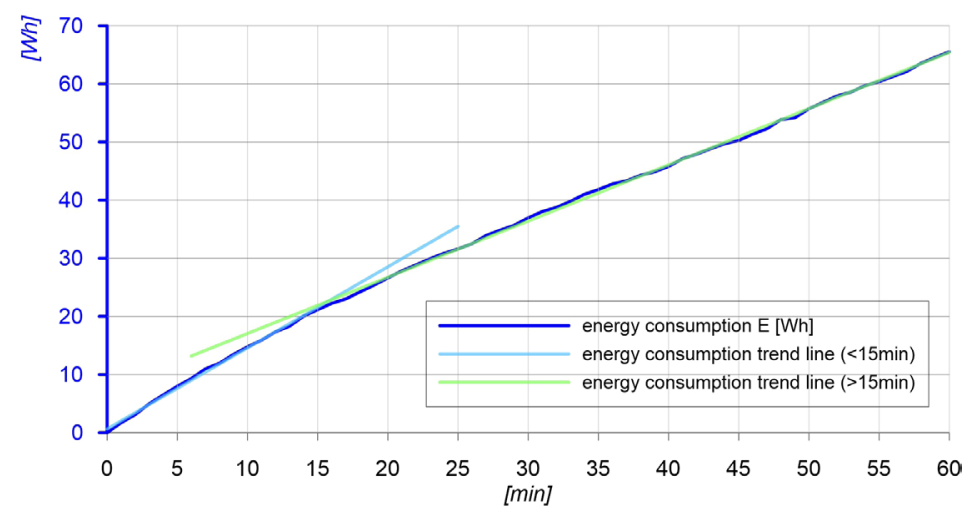

Fig. 5. Energy uptake $[\mathrm{Wh}]$ on the standby vs time

shutting off some ancillary systems in the lift, whilst it remains idle. Fig. 6 plots the energy consumption by the lift during its normal weekly duty cycle. The key factor influencing the energy uptake is the running mode. Besides, energy demands tends to decrease at weekends when the number of trips is decidedly lower and the lift operates mostly on the standby.

\section{ANALYSIS OF RESULTS}

Electric energy consumption by an analysed lift during its normal weekly duty cycle was found to be $21745 \mathrm{Wh}$ (Fig. 6). Registered data were used to develop histograms of an average hourly energy consumption (Fig. 7) and the number of trips (Fig. 8). Energy uptake in the first four 


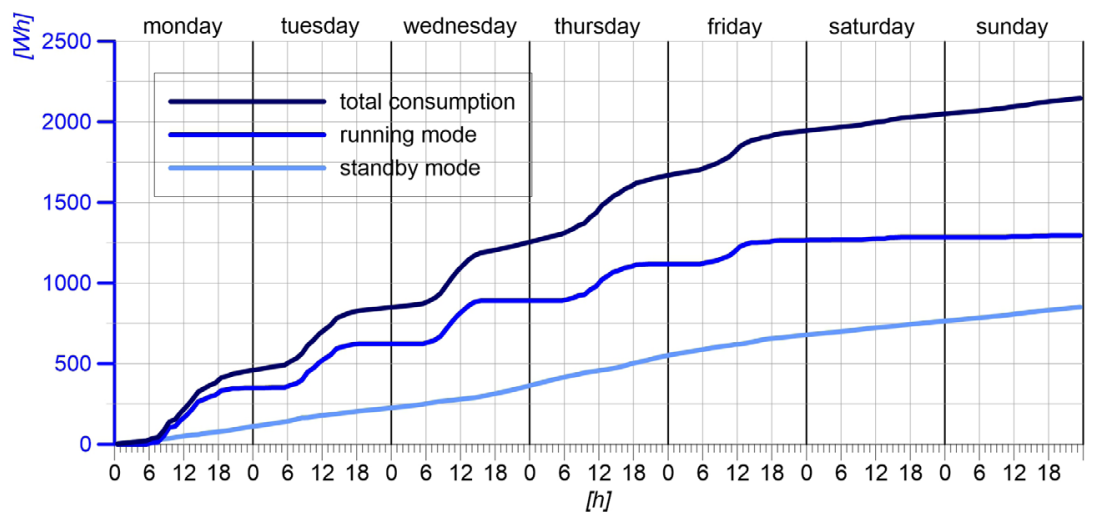

Fig. 6. Energy consumption [Wh] during the normal weekly duty cycle

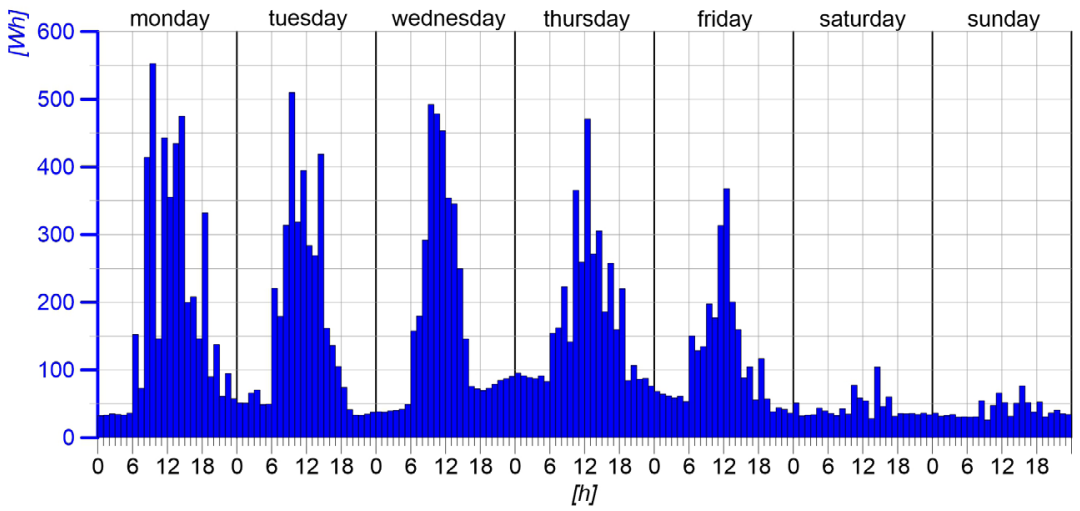

Fig. 7. Histogram of the average energy consumption per hour

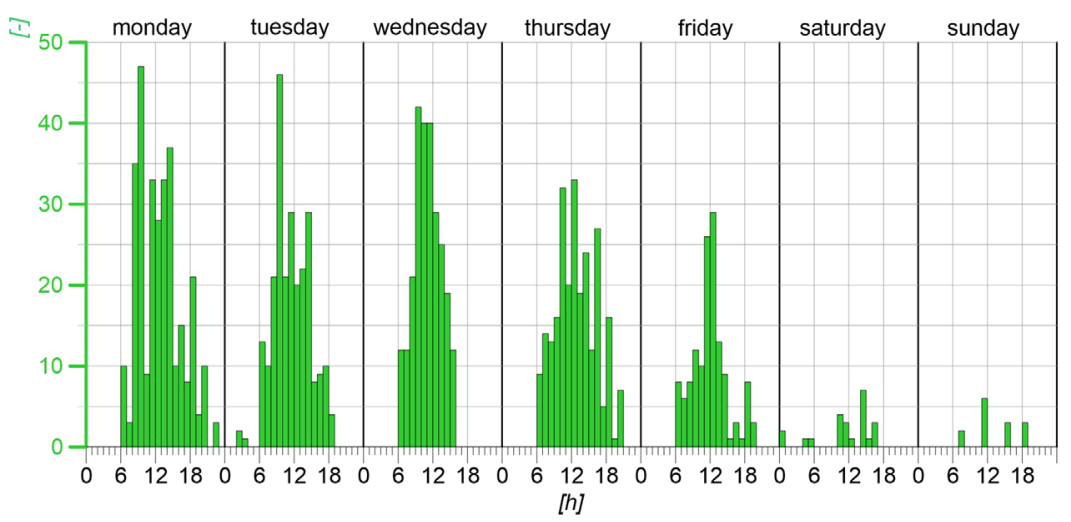

Fig. 8. Histogram of the average measured number of trips per hour within the weekly duty cycle

days of the week accounts for $78 \%$ to the total energy uptake. During those four days the number of trips is the greatest, which is attributable the majority of teaching classes being held on those days. On Fridays, the energy consumption tends to decrease significantly. Likewise, energy consumption is not high at weekends because there are only some part-time classes held. The aver- age energy consumption per day derived from the weekly duty cycle is $3067.9 \mathrm{Wh}$ and the averaged value for workdays (from Monday through Friday) becomes $3887.9 \mathrm{Wh}$.

The number of trips is found to be the highest on Mondays (306) and the lowest on Sundays (14). A clear correlation can be observed between the number of trips and energy consumed by the 


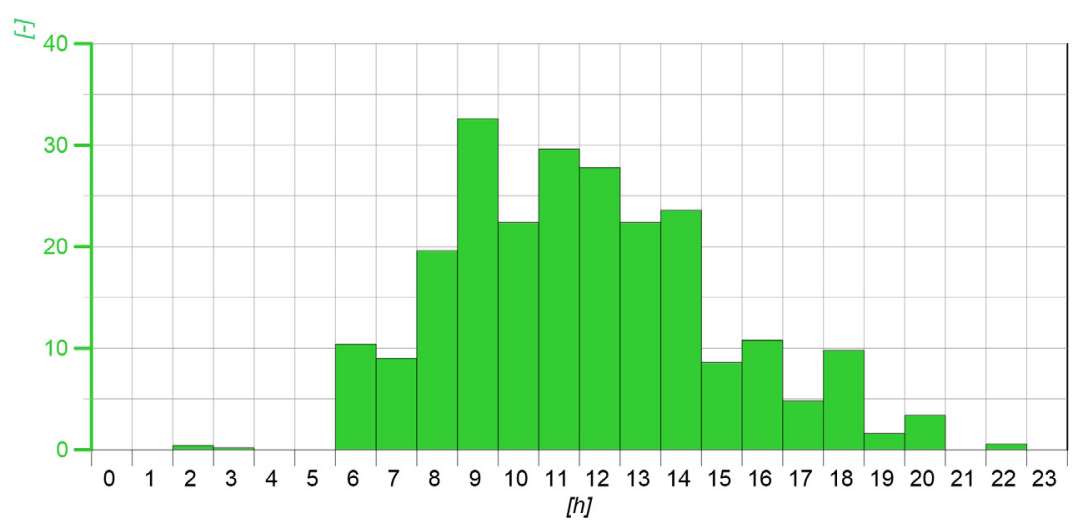

Fig. 9. Histogram of average number of trips per hour on workdays

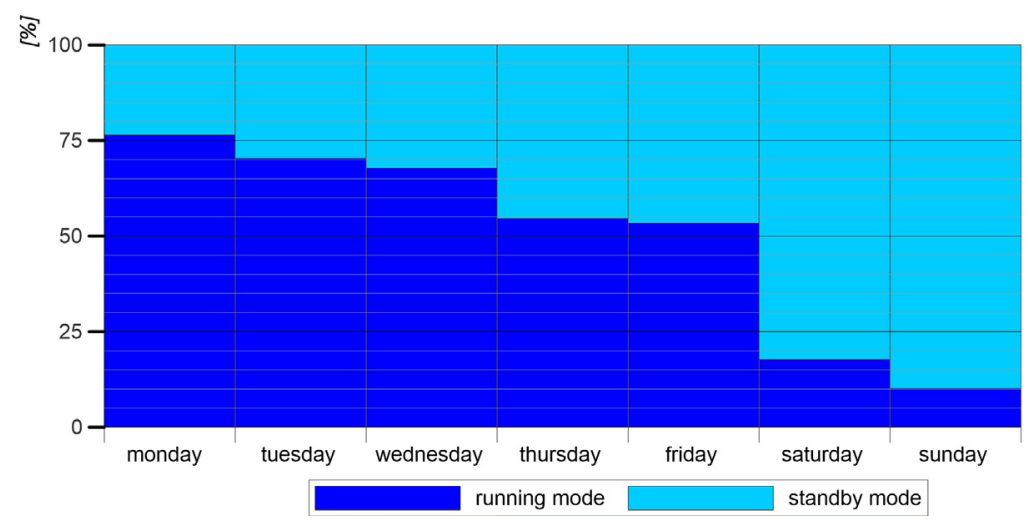

Fig. 10. Proportions of energy consumed in the running mode and on standby

lift. The average number of trips per day in the entire week is 175 , and 237 on workdays.

The average number of trips per hour being known, the operational characteristics of the lift can be obtained accordingly. On the account of the small number of trips registered at weekends, the average number of trips per hour is derived from values registered on workdays only (Fig. 9). The first trips are registered at 6 a.m. and the number tends to increase until 9 a.m., which is the peak operational time. Obviously, the first classes start at that hour. At 10 a.m. the number of trips decreases slightly and until 2 p.m the number more or less levels off 20. Between 3 p.m. and 8 p.m. there is little traffic, just several trips within one hour. Few and far between trips are registered between 9 p.m. and 6 a.m., which can be attributed to the security and maintenance staff in the building. The peak value (47 trips per hour) is registered on Monday at 9 a.m.

Energy uptake by the lift in the running mode is closely correlated with the usage frequency, the load carried, distance travelled and the direction of the ride. These factors should be recalled to account for the differences between energy uptake levels on Tuesdays, Wednesdays, Thursdays. The numbers of trips made on these days are similar whilst the power consumption on Tuesdays is higher by $21 \%$ than that registered on Thursdays. The average energy uptake in the running mode is $1858 \mathrm{Wh}$ (weekly), 2543.9 Wh (workdays), 143.1 (weekends). Energy consumed by the lift on each day in the running mode fluctuates around the mean value 1209.9 Wh (whole week), 1344.0 Wh (workdays) and 874.6 Wh (weekends). Lower energy consumption on the standby at weekends can be attributable to integrated systems limiting power uptake whilst the lift remains idle for a longer time. At weekends, when the number of trips is decidedly smaller than on workdays and the lift remains idle much longer, energy consumption is found to be nearly $40 \%$ lower.

The proportions of energy consumed in the running mode and on standby are shown in Fig 10. On Mondays, when the lift is most intensively used, this ratio is equal to $76 \%$. The other extreme 


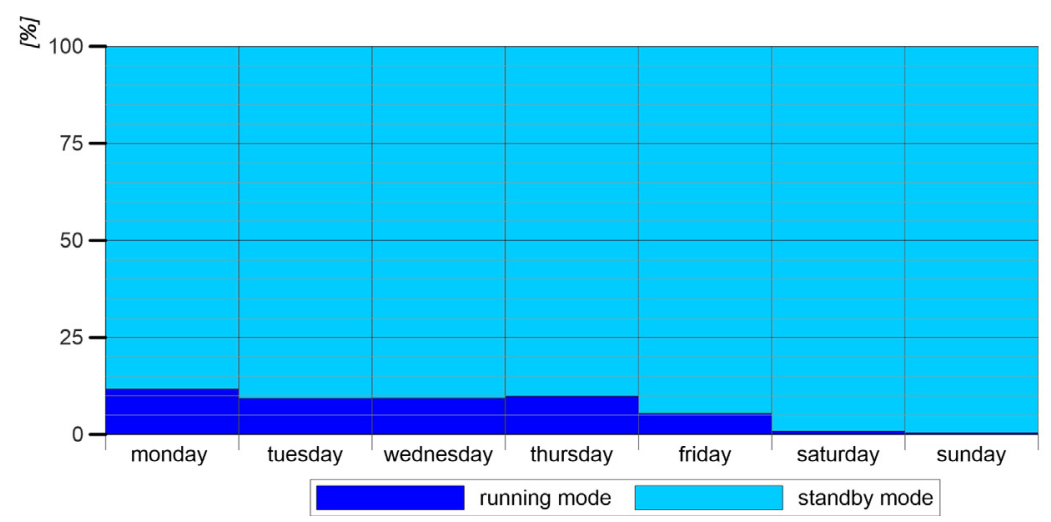

Fig. 11. Contribution of lift operation in the running mode and on standby

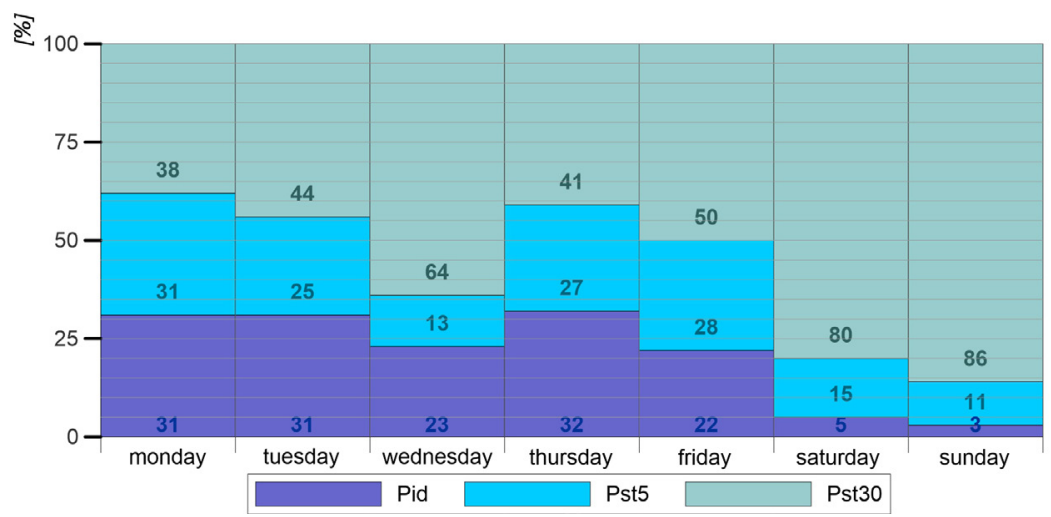

Fig. 12. Proportions of standby and idle times

value is registered for Sundays, with $10 \%$ contribution of energy consumed in the running mode.

On Monday the contribution of the energy consumed in the running mode is $76 \%$ even though the lift operation in this mode accounts only for $12 \%$ of the time. On Sundays the lift travels for $0.5 \%$ of the total time whilst the average value for the entire installation is $6.7 \%$ (Fig 11).

The standard PN EN ISO 25745-2 [19] provides the requirement that the actual proportions (percentage fractions) between the running times and idle periods should be duly accounted for. It defines three standby modes differing by the time elapsed since the lift's most recent movement $\left(\mathrm{P}_{\text {id }}\right.$ - idle, $\mathrm{P}_{\text {st5 }}$ - standby after 5-30 minutes (standby mode I) and $\mathrm{P}_{\mathrm{st30}}$ - standby after 30 minutes or more (standby mode II) ). The larger the number of trips, the higher proportion of idle time $\mathrm{P}_{\text {id }}$. It has been shown that on workdays the lift remains in the standby mode $\mathrm{P}_{\mathrm{s} 30}$ in the night time only. At the weekends, however, there are long breaks between infrequent rides (30 minutes or longer) and hence the contribution of the standby mode II will dramatically increase. For Mondays, the proportions of standby modes are similar (31\% - idle time, $31 \%$ - standby mode I, 38\%- standby mode II). The running/idle time pattern for Sundays is: $3 \%$ - idle time, $11 \%$-standby mode I, $86 \%$ - standby mode II) (Fig. 12).

This analysis clearly reveals two distinct lift usage patterns: intensive traffic on workdays and minimum - level duty at weekends. During the peak operational times, the lift makes 237 trips daily on the average (operating time 2.88 hours), hence it should be assigned to the 3rd class usage category in accordance with PN-EN ISO 25745-2 [19] or to the 2nd class usage category in accordance with the VDI4707 guidelines [27]. There are few trips at weekends (18 trips daily on the average, operating time 0.12 hours), which implicates the 1st (lowest) usage category in accordance with the two guidelines.

In accordance with the guidelines provided in $[4,19,27]$ the energy consumption was established and the lift was assigned to the energy efficiency class. To account for the differences 
Table 2. Energy consumption per day predicated in accordance with the guidelines provided in Project E4 [4], VDI 4707 [27], PN-EN ISO 25745 [19] alongside measurement data

\begin{tabular}{|c|c|c|c|c|}
\hline Energy consumption & Project E4 & VDI 4707 & PN-EN ISO 25745-2 & Measurements (mean value) \\
\hline \multicolumn{5}{|c|}{ Peak traffic - Monday through Friday } \\
\hline Running mode [Wh] & 1721,21 & 17665,55 & 3379,52 & 2543,9 \\
\hline Standby mode [Wh] & 2164,49 & 2248,95 & 1614,14 & 1344,0 \\
\hline Total [Wh] & 3885,70 & 4015,50 & 4993,66 & 3887,9 \\
\hline \multicolumn{7}{|c|}{ Minimum traffic - weekends } \\
\hline Running mode [Wh] & 87,15 & 706,62 & 563,25 & 143,1 \\
\hline Standby mode [Wh] & 2290,10 & 2277,66 & 1626,57 & 1017,7 \\
\hline Total [Wh] & 2377,25 & 2984,28 & 2189,82 & 1858,0 \\
\hline \multicolumn{7}{|c|}{ Monday through Sunday } \\
\hline Running mode [Wh] & 1270,94 & 1766,55 & 1408,13 & 1209,9 \\
\hline Standby mode [Wh] & 2199,11 & 2248,95 & 1644,88 & 3067,9 \\
\hline Total [Wh] & 3470,05 & 4015,50 & 3053,01 & \\
\hline
\end{tabular}

Table 3. Lift energy efficiency category according to VDI 4707 [27] and PN-EN ISO 25745 [19]

\begin{tabular}{|c|c|c|c|}
\hline & VDI 4707 & & PN-EN ISO 25745-2 \\
\hline Energy efficiency class running mode & D & Performance level running mode & 5 \\
\hline Energy efficiency class standby mode & B & Performance level standby mode & 2 \\
\hline Lift energy efficiency class & C & Lift energy efficiency class & C \\
\hline
\end{tabular}

in the lift operation patterns, the calculation procedure used averaged numbers of trips per week obtained for the period from Monday through Friday and at the weekends.

\section{CONCLUSIONS}

The lift has been assigned to the energy efficiency class $\mathrm{C}$ (Table 3 ), its energy performance and operational characteristics were determined accordingly. Measurement data reveal two distinct usage patterns: peak operational times on workdays and low-intensity usage at weekends. For each usage pattern the energy consumption was measured and predicted recalling the applicable guideline documents. Even though the lift has been duly assigned to a usage category, the applied calculation procedures fail to provide correct energy consumption estimates. In order to reliably establish the energy efficiency ratings of a given lift installation, its energy performance and operating parameters have to be measured under the normal service conditions.

\section{REFERENCES}

1. Adoption of the Paris agreement, United Nations, December 2015.
2. Al-Sharif L. Lift Energy Consumption: General Overview (1974-2001). Elevator World, 52 (10), 2004, 61-67.

3. Almeida A., Hirzel S., Patrão C., Fong J., Dütschke. Energy-efficient elevators and escalators in Europe: An analysis of energy efficiency potentials and policy measures. Energy and Buildings, 47, 2012, 151-158.

4. Almeida A., Araujo N., Fong J., Nunes U., Patrao C., et al. E4 - Energy Efficient Elevators and Escalators.Grant agreement no. EIE/07/111/ SI2.466703, 2010.

5. Barney G. Method to calculate the energy consumption of lifts. Elevatori, 2013, Sept./Oct, 36-41.

6. Conclusions on 2030 Climate and Energy Policy FrameworkSN 79/14, European Council, 2014

7. Doolaard D.A. Energy consumption of different types of lift drive system. Elevator Technology 4, 1992, 77-85.

8. Funai K., van Schijndel-de Nooij M., van Nunen E. Influence of Elevator Acceleration Induced Loading on Injury Levels, Elevator World, 58 Issue 5, 2010, 86-98.

9. Herrera I., Kaczmarczyk S. The assessment of vibration absorption capacity of elevator's passengers. Journal of Physics: Conference Series, 2009; 181, No.1: 1-8.

10. Lonkwic P., Gardyński L. Testing Polymer Rollers Memory in the Context of Passenger Lift Car Comfort, Journal of Vibroengineering, 1, 2014, 225-230. 
11. Lonkwic P., Syta A. Nonlinear analysis of braking delay dynamics for the progressive gears in variable operating conditions. JOURNAL OF VIBROENGINEERING Volume: 18 Issue: 7 Pages: 4401-4408.

12. Lonkwic P, Różyło P, Dębski H. Analysis of the loading impact on the stresses value of the progressive gear body with the use of finite-element method. EksploatacjaiNiezawodnosc - Maintenance and Reliability, 17(4), 2015, 542-548.

13. Lonkwic P., Szydlo K., Molski S. The impact of progressive gear geometry on the breaking distance length under changeable operating conditions, Advances in Science and Technology-Research Journal. Volume 10 (29), Pages: 161-167.

14. Lonkwic P.,Szydło K. Reduction of the cabin acoustic emission by the selection of an optimum stiffening method for the cabin panels. Journal of Measurements in Engineering, Volume: 4 (2), Pages: 95-102.

15. Lorente, A.M., Gomez, A., Diaz, D., Arteche, F. State of the Art Calculation Methods for Elevator Energy Consumption. Elevator Technology, 18, 2010, 225-238.

16. Magiera T., Kułaga P., Wójcik K. Analysis and Assessment of Dynamic Response to Passengers During Lift Emergency Braking. Advances in Science and Technology Research Journal. 2017;11(3):164-171.

17. Nipkow J. Electricity consumption and efficiency potentials of lifts. Report of Swiss agency for efficient energy use S.A.F.E. Zurich: HTW Chur University of Applied Sciences 2005.

18. PN-EN ISO 25745-1:2013. Charakterystyka energetyczna dźwigów, schodów i chodników ruchomych - Część 1: Pomiar zużycia energii i weryfikacja.
19. PN-EN ISO 25745-2:2015. Efektywność energetyczna dźwigów, schodów i chodników ruchomych -- Część 2: Obliczanie energii i klasyfikacja dźwigów (wind).

20. Protokół z Kioto do Ramowej konwencji Narodów Zjednoczonych w sprawie zmian klimatu, sporządzony w Kioto dnia 11 grudnia 1997 r., Dziennik Ustaw 2005, nr 203, poz. 1684.

21. Sachs H.M. Opportunities for Elevator Energy Efficiency Improvements. American Council for on Energy-Efficient Economy, Washington, DC, 2005.

22. Schroeder J. The energy consumption of elevators A comparative Analysis. Elevator Technology, 11, 1980, 28-31.

23. Schroeder J.The energy consumption of elevators. Elevator Technology 1986.

24. SchroederJ.Energy Consumption and Power Requirements of Elevators. Elevator World March 1986.

25. Schroeder J.Second Century of the Skyscraper Council on Tall Buildings and Urban Habitat, Energy Consumption and Power Requirements of Elevators. (pp. 621-627), 1988 Springer, Boston, MA.

26. SIA 380/4 Elektrische Energie im Hochbau.

27. VDI 4707 Part 1. Energy Efficiency Label for Elevators.

28. VDI 4707 Part 2. Energy Efficiency Label for Elevators - components.

29. White L.E. Energy consumption: Hydraulic elevators and traction elevators. Elevator World April 1984.

30. Wolszczak P., Łygas K., Lonkwic P., Molski Sz., Litak G. Braking deceleration variability of progressive safety gears using statistical and wavelet analyses. Measurement, Volume: 110, Pages: 90-97. 